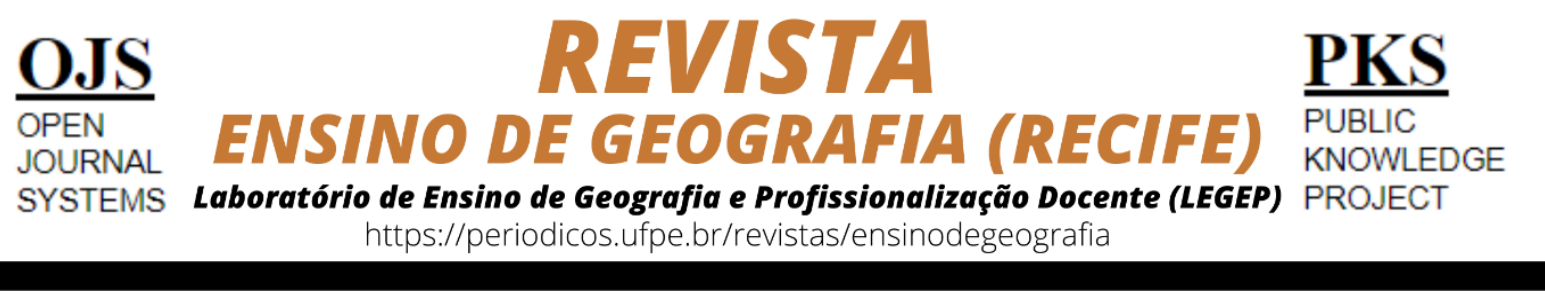

\title{
O PERCURSO FORMATIVO DO CURSO DE LICENCIATURA EM GEOGRAFIA: A FORMAÇÃO DA IDENTIDADE PROFISSIONAL DOCENTE
}

\author{
Carolina Araújo Michielin¹, Rosa Elisabete Militiz Wypyczynski Martins²
}

\begin{abstract}
${ }^{1}$ Mestranda no Programa de Pós Graduação em Educação (PPGE) da Universidade do Estado de Santa Catarina. Contato: carolinaa.michielin@gmail.com - ORCID iD: http://orcid.org/0000-0002-1671-3801.

2 Professora do Departamento de Geografia da Universidade do Estado de Santa Catarina - FAED/UDESC e do Programa de Pós Graduação em Educação (PPGE). Contato: rosamilitzgeo@gmail.com - ORCID iD: http://orcid.org/0000-0002-2875-2883.
\end{abstract}

Artigo recebido em 06/04/2020 e aceito em 23/04/2020

\begin{abstract}
RESUMO
A pesquisa aqui apresentada é resultado do trabalho de conclusão do curso de Geografia Licenciatura da Universidade do Estado de Santa Catarina (UDESC), na qual se insere pela discussão acerca da importância e relevância dos currículos de Geografia Licenciatura e do Projeto Pedagógico do Curso da Universidade do Estado de Santa Catarina e do Centro de Ciências Humanas e da Educação (FAED - UDESC). O trabalho compreende um caráter bibliográfico e documental, girando em torno de referenciais que abordam a influência dos currículos na formação de professores e professoras e sua identidade docente, tendo como finalidade e objetivo compreender de que forma a organização do Projeto Pedagógico do Curso (PPC) e o desenho curricular do curso contribui para a construção da identidade docente. Esta pesquisa apontou que os desenhos curriculares e os atravessamentos do percurso de formação são fundamentais na constituição da identidade profissional docente.

Palavras-chave: Formação de professores; Identidade docente; Currículo; Geografia Licenciatura.
\end{abstract}

\section{THE FORMATIVE PATH OF THE DEGREE COURSE IN GEOGRAPHY: THE FORMATION OF THE TEACHING PROFESSIONAL IDENTITY}

\begin{abstract}
The research presented here is the result of the conclusion work of the University of the State of Santa Catarina (UDESC) of Geography in bachelor's degree, in which it is inserted by the discussion about the importance and relevance of the Geography in bachelor's degree curricula and the Pedagogical Project of the Course of the University of the State of Santa Catarina and Center for Humanities and Education (FAED - UDESC). The work comprises a bibliographic and
\end{abstract}


documentary character, revolving around references that address the influence of curricula on the formation of teachers and their teaching identity, with the purpose and objective of understanding how the organization of the Pedagogical Course Project (PPC) and the curricular design of the course contributes to the construction of the teaching identity. This research pointed out that the curricular designs and the crossing of the formation path are fundamental in the constitution of the teaching professional identity.

Keywords: Teacher training; Teaching identity; Curriculum; Geography Degree.

\title{
EL CURSO FORMATIVO DEL CURSO DE GRADO EN GEOGRAFÍA: LA FORMACIÓN DEL PROFESOR DE IDENTIDAD PROFESIONAL
}

\begin{abstract}
RESUMEN
La investigación presentada aquí es el resultado de la finalización del Curso de Geografía Grado de la Universidad del Estado de Santa Catarina (UDESC), que forma parte de la discusión sobre la importancia y pertinencia de los planes de estudios de Grado en Geografía y el Proyecto Pedagógico del Curso de la Universidad Estatal de Santa Catarina y el Centro de Humanidades y Educación (FAED - UDESC). La obra comprende un carácter bibliográfico y documental, girando en torno a referencias que abordan la influencia de los planes de estudio en la educación de los profesores y su identidad docente, con el propósito y el objetivo de entender cómo la organización del Proyecto Pedagógico del Curso (PPC) y el diseño curricular del curso contribuye a la construcción de la identidad del profesorado. Esta investigación señaló que los dibujos curriculares y los cruces del curso de formación son fundamentales en la constitución de la identidad profesional del profesor.

Palabras clave: Formación del profesorado; Identidad del maestro; Currículo; Grado en Geografía.
\end{abstract}

\section{INTRODUÇÃO}

O presente trabalho trata-se de um fragmento uma pesquisa mais ampla referente a um trabalho de conclusão do curso de Geografia Licenciatura do Centro de Ciências Humanas e da Educação (FAED) da Universidade do Estado de Santa Catarina (UDESC) no qual se constitui como fruto de uma inquietação acadêmica de reconhecer a historiografia do curso de Licenciatura em Geografia. Constituindo-se assim como o foco principal desta pesquisa a análise do currículo de Licenciatura em Geografia da FAED - UDESC e de seu Projeto Pedagógico, com ênfase na última reforma curricular que ocorreu em 2014.

Quando relacionadas a discussões referentes à formação de professores, pesquisas questionam e evidenciam que os cursos que promovem uma formação que reproduz um currículo formal , constando atividades e estágios que, ao invés de relacionar e criar pontes entre a academia e a escola, optam por trabalhar em "uma perspectiva burocrática e cartorial que não dá conta de captar as contradições presentes na prática social de educar, pouco têm contribuído para gestar uma nova 
identidade do profissional docente" (PIMENTA, 1999, p. 16). Em consonância a esse e outros questionamentos, esta pesquisa se justifica, para além de uma motivação pessoal, mas para identificar as transformações e pretensões resultantes das mudanças curriculares do curso de Geografia da FAED - UDESC, que foram fundamentais para produção de conhecimentos e princípios que definiram o perfil da formação inicial do/da professor/a de Geografia.

A problemática que me leva a produzir esta pesquisa é intermediada por minha justificativa, que busca depreender de que maneira os desenhos curriculares, do curso de Geografia Licenciatura, contribuíram para a formação da identidade docente dos futuros professores e professoras do curso? A fim de desvendar o problema desta pesquisa e percorrer essa trajetória identitária da formação docente, estabeleço o objetivo de compreender de que forma a organização do PPC e o desenho curricular, implantado em 2014, do curso de Geografia Licenciatura contribui para a formação da identidade docente. Com o propósito de garantir que o objetivo geral seja concretizado, estipulo alguns objetivos específicos: investigar como as Diretrizes Curriculares Nacionais de formação de professores/as e as políticas públicas impactaram na organização curricular dos cursos de licenciatura no Brasil; identificar a importância e a construção da identidade docente nos cursos de licenciatura e analisar o desenho curricular e o Projeto Pedagógico do Curso (PPC) de Geografia Licenciatura do Centro de Ciências Humanas e da Educação da Universidade do Estado de Santa Catarina de 2014, com o intuito de reconhecer como o mesmo influencia na construção da identidade docente de professores e professoras.

Quanto aos procedimentos metodológicos para desenvolver a pesquisa, opto por uma pesquisa de caráter bibliográfico e documental, pois me debruço sobre revisões bibliográficas e referenciais teóricos que colaboraram para as considerações de minha problemática. Também se desenvolve fundamentada em uma pesquisa documental, tendo em vista que utilizo de análises documentais, com o intuito de identificar o perfil da formação docente do curso de Geografia Licenciatura da FAED - UDESC, por meio da análise dos desenhos curriculares e do PPC do curso de licenciatura de geografia implantado em 2014.

Essa pesquisa não procura e nem se preocupa em conceber uma verdade a respeito dos currículos ou sobre a formação de professores de Geografia, pois não se tem aqui o intuito de arquitetar uma utopia entorno da grade curricular de um curso. Tampouco procura determinar que a reformulação curricular seja concebida como a solução de todos os problemas que circundam a implantação de um curso de formação de professores/as. 
Desta forma, propõe-se aqui uma problematização acerca da organização curricular do curso de Geografia Licenciatura da FAED - UDESC, frente às demandas da realidade educacional brasileira, que necessita a organização de cursos de formação inicial de professores/as que assegurem uma formação sólida capaz de dar conta da construção da identidade docente para a atuação profissional no sentido de atender às necessidades e interesses dos/das estudantes e as demandas da educação básica. Compreende-se ainda que a organização curricular aqui discutida - e mesmo o próprio PPC do curso de Geografia Licenciatura - são fundamentais neste processo de profissionalização dos/as professores/as, todavia estas demandas não garantem e nem são responsáveis pela solução dos problemas educacionais, principalmente no âmbito da Educação Básica brasileira.

\section{ORGANiZAÇÃo CURRICULAR PARA FORMAÇÃo DE PROFESSORES/AS E A CONSTRUÇÃO DE SUA IDENTIDADE PROFISSIONAL}

Segundo Masson (2009) a década de 1980 reflete um momento de mudanças significativas na discussão acerca das construções de alternativas para o ensino no Brasil. As transformações na sociedade brasileira, a partir dessa década, são ocasionadas pelo contexto político do país que advém de um período de democratização do Estado. Esta conjuntura resultou em uma série de ações que culminaram com a aprovação da Lei de Diretrizes e Bases da Educação Nacional de 1996 (LDB/96) e as sucessivas medidas complementares a esta que direcionaram a organização da Educação Básica e superior no Brasil.

Para Dourado (2002), a LDB é entendida como uma lei complementar que passa a regulamentar as diretrizes e bases que permeiam a educação nacional, no qual destaca desde a gratuidade e a gestão democrática em todos os níveis da escola pública, até a dinâmica entre pesquisa, ensino e extensão no contexto universitário. A LDB, quando voltada para a educação universitária, ressalva um conjunto de políticas que apontam alteração para esse nível superior de ensino, que, para Dourado (2002), se constituem, paradoxalmente, a partir de processos de flexibilização e descentralização, dentro da camada legislativa, e por outro lado também se estabelece por novas maneiras de controle, além da padronização, por meio de "processos avaliativos estandardizados" (DOURADO, 2002, p. 242).

Entre as alterações que estão dispostas na LDB, são apontadas as Diretrizes Curriculares Nacionais voltadas para a formação docente, estas já previstas na Lei n ${ }^{\circ}$ 9.131/1995 de constituição do Conselho Nacional de Educação (CNE) e também no Parecer CNE n 776/1997, que passam a 
determinar as orientações para a formulação das diretrizes gerais de todos os cursos de graduação no país (SILVA, 2016).

As Diretrizes Curriculares Nacionais (DCN), direcionadas para a Formação de Professores e Professoras da Educação Básica, "propõe como objetivo principal a apresentação de uma base comum de formação docente enunciado em diretrizes que são capazes de revisar os modelos em vigor propostos até então" (SCHEIBE, BAZZO, 2013, p. 21). Estes modelos anteriores à implantação destas diretrizes se caracterizavam pela fragmentação e dicotomia, quando relacionados os conteúdos e práticas metodológicas, além de representarem a complexidade da articulação entre os processos formadores, estes coordenados pelas IES, e os trabalhos realizados pelas escolas de Educação Básica no país.

As DCNs surgiram com a intenção e tentativa de implantar novas ações que atuassem diretamente na formação de professores e professoras, voltados para a Educação Básica na esfera do ensino superior. Volsi (2016) destaca que as implementações das DCNs para a formação docente, em cursos de formação inicial e continuada, representam um desafio para as políticas educacionais que são voltadas aos professores e professoras da atualidade, visto que muitas das ações necessitam ser desenvolvidas pelas instituições formativas, seja pelo Ensino Superior ou pela Educação Básica, para que, dessa forma, as orientações e normativas das DCN se materializem. As novas diretrizes curriculares asseguram, ainda, princípios e buscam contribuir para com a melhora na formação inicial e continuada dos profissionais da Educação ao definirem uma base comum nacional, além de enfatizarem a necessidade de articulação entre a Educação Básica e o Ensino Superior.

Com a aprovação das Diretrizes Curriculares Nacionais para a formação inicial de professores e professoras decorreu-se a necessidade de reorganização dos currículos das licenciaturas no país, que contribuíram para a qualificação do trabalho docente de professores e professoras que constituem as diferentes áreas de conhecimento dos anos finais do Ensino Fundamental e também do Ensino Médio, entre eles os de Geografia (SILVA, 2015). A Resolução CNE n 1/2002, que estabelece as diretrizes curriculares nacionais para a formação de professores, não trata das particularidades das diferentes áreas específicas de formação, apenas normatiza a estrutura dos currículos. Já, a Resolução CNE 14/2002, estabeleceu as diretrizes curriculares para os cursos de Geografia. De acordo com o Art. $1^{\circ}$ As Diretrizes Curriculares para os cursos de Geografia, integrantes dos Pareceres CNE/CES 492/2001 e 1.363/2001, devem orientar a organização dos projetos pedagógicos destes cursos. As DCNs destacam também a importância da formação de profissionais e professores/as reflexivos e 
capazes de entender e relacionar o seu lugar no mundo com um itinerário formativo pautado na interrelação entre os elementos didáticos e pedagógicos e os conhecimentos específicos da geografia.

Tendo em vista estas considerações em relação aos debates acerca da formação de professores, toma-se a discussão sobre sua identidade docente. "A identidade não é um dado imutável. Nem externo, que possa ser adquirido. Mas é um processo de construção do sujeito historicamente situado" (PIMENTA, 1999, p.18). A identidade profissional do professor é uma concepção que perpassa toda a vida profissional do sujeito, no qual a mobilização dos saberes da experiência - um dos saberes da docência de Pimenta (1999) - corrobora para a construção de tal identidade.

Uma identidade profissional se constrói, pois, a partir da significação social da profissão; da revisão constante dos significados sociais da profissão; da revisão das tradições. Mas também da reafirmação de práticas consagradas culturalmente e que permanecem significativas. Práticas que resistem a inovações porque prenhes de saberes válidos às necessidades da realidade. Do confronto entre as teorias as práticas, da análise sistemática das práticas à luz das teorias existentes, das construções de novas teorias. Constrói-se também, pelo significado que cada professor, enquanto ator e autor, confere à atividade docente no seu cotidiano a partir de seus valores, de seu modo de situarse no mundo, de sua história de vida, de suas representações, de seus saberes, de suas angústias e anseios, do sentido que tem em sua vida o ser professor (PIMENTA, 1999, p. 19).

\footnotetext{
Em síntese, a identidade docente se encontra em uma incessante metamorfose. A construção da identidade profissional é uma das premissas para que ocorra a profissionalização do professor, no qual "envolve o delineamento da cultura do grupo de pertença profissional, sendo integrada ao contexto sociopolítico" (VEIGA, 2006, p.472).
}

A estruturação de uma individualidade docente é uma concepção que permeia por toda a vida profissional, desde o momento da escolha da profissão perpassando por sua formação inicial e continuada, além dos distintos espaços institucionais e instâncias que contribuem e desenvolvem esse processo. (VEIGA, 2006.)

No contexto dos cursos de licenciatura e formação docente é preciso oportunizar espaços que valorizem a dimensão prática, possibilitando os/as estudantes a construção de saberes articulados com a teoria. Neste sentido, as propostas pedagógicas e curriculares dos cursos de formação inicial de professores/as têm que priorizar a articulação entre teoria e a prática, pois são dimensões basilares e indissociáveis na constituição do processo de formação do/a professor/a que contribuem para o entendimento das relações sociais, políticas e econômicas da sociedade, preparando-o para o fazer profissional e para a compreensão das transformações no mundo do trabalho. 
Dessa forma, compreende-se que a identidade profissional docente é inserida em um contexto intrínseco à construção social do conhecimento, pois é estabelecida, em sua consolidação e constituição, através de processos que partem de uma origem individual, todavia são vigorosamente influenciados por vivências sociais e as informações determinadas no mundo atual (SILVA; MANO, 2018).

\section{A IDENTIDADE PROFISSIONAL DOCENTE RETRATADA NOS DESENHOS CURRICULARES: UMA ANÁLISE BASEADA NO PPC DO CURSO}

O papel fundamental do Centro de Ciências Humanas e da Educação na Universidade do Estado de Santa Catarina, inicialmente, era o de formação de professores/as focados nas matérias especificas do curso Normal $-1^{\circ}$ e $2^{\circ}$ ciclos, constituição de orientadores educacionais para o Ensino Primário, além de pesquisadores/as educacionais e administradores/as escolares. A primeira etapa da trajetória do curso de Geografia se dá a partir da criação da Licenciatura Plena em Geografia no Centro de Ciências Humanas e da Educação que buscava a formação integral do/a estudante por meio da habilitação voltada tanto para a pesquisa, quanto para o Ensino de Geografia.

Á vista disso o curso de Estudos Sociais foi criado em resposta as diretrizes educacionais que permeavam pelo contexto político da época - a ditadura militar - tendo seus trabalhos iniciados na década de 1974, que compreendia a habilitação para lecionar História, Geografia, Organização Social e Política do Brasil (OSPB), além de Educação Moral e Cívica (EMC). Foi somente no final da década de 1990 que o curso de Geografia passa a ter a possibilidade de dupla habilitação, compreendendo tanto a Licenciatura como o Bacharelado, constituindo assim a primeira reformulação curricular no curso.

Sendo válido ressaltar aqui a preocupação que o curso de Geografia da FAED - UDESC, no período de sua primeira reformulação curricular, teve em atender as Resoluções CNE/CP 1/2002 e 2/2002 que instituem, respectivamente, as Diretrizes Curriculares Nacionais para a Formação de professores/as da Educação Básica, em nível superior nos cursos de licenciatura e a Resolução que instituiu a duração e a carga horária dos cursos de Formação de Professores/as, mesmo se constituindo ainda um curso voltado para a dupla habilitação. A próxima mudança curricular se deu a partir de uma determinação do Conselho Estadual de Educação de Santa Catarina, que passou a proibir os cursos de dupla habilitação no Estado. Dessa forma, em 2013, foi aprovado pelo CONSUNI 
(Conselho Universitário) a homologação para a constituição dos cursos com as habilitações específicas, logo, criou-se os cursos de Geografia Licenciatura e Geografia Bacharelado com grades curriculares distintas e entradas semestrais intercaladas, tendo, no primeiro semestre de 2014 o ingresso da $1^{\circ}$ turma de Licenciatura e, no segundo semestre, de Bacharelado.

A partir desta determinação, foi iniciado o processo de elaboração de um novo Projeto Pedagógico do Curso de Graduação em Geografia Licenciatura, que foi aprovado em 2013, através da Resolução CONSUNI/UDESC n. 043/2013. Considera-se que o Projeto Pedagógico de um curso "tem a finalidade de direcionar todas as ações dentro do curso, para isso, ele precisa ser construído de forma coletiva com objetivos claros e possíveis de serem executados" (OLIVEIRA, 2016, p. 167). O PPC do Curso de Geografia Licenciatura (2013), além de atender as novas Resoluções do CNE e do CONSUNI/UDESC, foi elaborado com o propósito de estar em sintonia com as questões da docência na Educação Básica e com as políticas educacionais.

Para ser arquitetado, o PPC deve ser concebido e desenvolvido como uma prática social coletiva, dessa forma pode constituir "fortes sentimentos de pertença e identidade" (VEIGA, 2004, p. 16). O projeto não pode existir sem o protagonismo dos professores/as, estudantes e pesquisadores/as, visto que é dessa maneira que a universidade constrói sua identidade institucional. Sendo assim deve-se "usar os princípios da flexibilidade e da autonomia, de modo a desenvolver identidades mais distantes da padronização burocrática, capazes de instituir e implementar projetos políticos-pedagógicos próprios" (VEIGA, 2004, p. 16).

Com a intenção de compreender de que forma a identidade docente pode ser retratada nos desenhos curriculares analisamos a contribuição do PPC do curso de Geografia Licenciatura da FAED. Optamos por subdividir os capítulos do documento em dois momentos nesta pesquisa. O primeiro diz respeito aos objetivos do curso e o perfil profissional dos egressos, enquanto o outro aborda a proposta pedagógica a qual se divide nas questões acerca dos desenhos curriculares, ementa das disciplinas e a influência das DCNs na formação de professores/as em Geografia.

A escolha dos dois subcapítulos do PPC (2013) - objetivos do curso e perfil profissional se desenvolve a partir da problemática estabelecida inicialmente neste trabalho: de que maneira os desenhos curriculares e o PPC, do curso de Geografia Licenciatura, contribuíram para a formação da identidade docente dos futuros professores e professoras do curso? Acreditamos que ao analisar estes subcapítulos é possível investigar se estes dois itens do PPC contribuem para responder nossa 
problemática e se indicam que este PPC do curso de Geografia Licenciatura está voltado para a formação da identidade docente dos/as estudantes que serão futuros/as professores/as.

Dito isso, incorporado ao Projeto Pedagógico do Curso de Graduação em Geografia Licenciatura encontram-se os Objetivos do Curso de Geografia Licenciatura, aqui é estabelecido como objetivo geral do curso a formação do professor/educador do ensino da Geografia. O PPC (2013) ainda determina que seja função da Geografia descrever e analisar a combinação de alguns elementos, tanto naturais quanto sociais, compreender a realidade geográfica, articulando o âmbito teórico e empírico.

Com a construção do PPC do ano de 2013, que culminou na dissociação do bacharelado com a licenciatura, propõe-se um perfil profissional destinado a formação de professores/as voltados para a atuação na Educação Básica. O perfil profissional contribui para a formação e consolidação de uma identidade docente quando atua, durante o processo formativo, diante da autocrítica e autonomia da própria prática docente do estudante - consequentemente do/a futuro/a professor/a de Geografia sendo ainda influenciada a partir de um contexto que aborda o social, o cultural e também o político (ROCHA; BRAGA; SANTOS, 2014). Para Campos (2012) um dos obstáculos encontrados na formação docente é a identificação do estudante para com a profissão, o que futuramente molda a sua identidade profissional e também o próprio perfil do egresso, que era dificultada a partir da consideração de um curso com dupla habilitação, no caso, anteriormente a atual reforma curricular.

Com a atual reforma a matriz curricular que foi proposta, e hoje se encontra em vigência, contempla claramente a legislação trazida pelas DCNs de 2002, uma vez que apresenta os requisitos legais e seus desenhos curriculares articulam os conteúdos básicos e complementares em núcleos específicos que se dispõem necessários a aquisição do conhecimento da ciência geográfica, percebese aqui a importância e relevância de uma reformulação na formação do licenciado em Geografia, na qual está “impõe uma matriz curricular que incorpore novas linguagens e as alterações definidas pelos instrumentos legais e pelo redimensionamento do campo de exercício profissional" (PPC, 2013, p. 17).

Sendo válido salientar que o curso de Geografia Licenciatura da FAED - UDESC ainda não atende as DCNs propostas e aprovadas pelo CP/CNE em 2015, sendo encabeçada pela Resolução CNE 02/2015, uma vez que a última reforma curricular do curso ocorreu em 2013 e teve sua primeira turma ingressa no primeiro semestre de 2014, no qual seus desenhos curriculares e o PPC constituemse como objetos de estudo desta pesquisa. 
O PPC traz no corpo de seu documento propostas que dissertam sobre o turno do curso de Geografia Licenciatura da FAED - UDESC, que atualmente se dispõe nos períodos vespertino e noturno, tendo o número de 40 vagas anuais com ingressos realizados alternadamente entre os turnos. Estas vagas podem ser oferecidas e preenchidas de maneiras distintas, primeiramente o ingresso pode ser efetuado pelo processo seletivo do vestibular da Universidade $X$, ou por transferência, reingresso ou retorno. Em relação à duração do curso e seu período de integralização, o PPC de 2013 propõe que o curso de Geografia Licenciatura deva ter duração mínima de 04 anos, ou seja, oito semestres, e seu período de integralização máximo é disposto por 07 anos, ambos os períodos determinados pela Resolução CNE/CES n 2/2007, que institui as cargas horárias mínimas dos cursos de graduação.

A reestruturação curricular do curso de Geografia Licenciatura da FAED - UDESC, proposta no PPC de 2013, aqui analisado, vêm em contrapartida desse movimento de pensar o curso de Licenciatura como anexo ao curso de bacharelado. A proposta de reformulação que se transformou no curso de Geografia Licenciatura faz mais do que apenas modificar a localização dos componentes curriculares nos tempos e espaços dos programas de formação, propõe uma ressignificação nos desenhos curriculares promovendo a articulação entre teoria e prática que corrobora na constituição de uma identidade profissional docente aos/as futuros/as professores/as de Geografia.

A Matriz Curricular Proposta no PPC de 2013 prevê a formação da habilitação Licenciatura e, assim como a antiga estrutura, a finalização do curso se dá completando 8 fases, sendo que sua carga horária total passa a ser de 3.402 horas/aula, correspondendo atualmente a 189 créditos, além de também ser construída pelo sistema de créditos de acordo com a Resolução 025/2006 - CONSEPE que estabelece que cada crédito tem 18 horas/aula.

Os cursos de formação docente têm o desafio de repensar seus desenhos curriculares para que possam fazer frente às transformações do cenário contemporâneo. É necessário possibilitar ao/a futuro/a professor/a, a construção de uma identidade profissional que corresponda às exigências de um contexto social, histórico, político e cultural onde se desenvolve a prática pedagógica. É preciso investir numa formação que vincule teoria e prática, que promova a aproximação entre o espaço da escola e os contextos de formação acadêmica, para haver uma efetiva inserção na cultura da escola que será o ambiente de trabalho deste/a professor/a. Assim, fica evidente que o processo de formação requer, além do domínio do conhecimento da área específica e do conhecimento da área pedagógica, uma vivência curricular pautada na articulação entre o ensino superior e a Educação, com um projeto de formação estruturado com os sistemas ou redes de ensino e instituições de Educação Básica. 
Dessa forma, para compreender como a identidade profissional docente é constituída, no âmbito universitário, fomos além do PPC do curso, dando ênfase na estrutura e desenhos curriculares vigentes no curso de Geografia Licenciatura. Sendo assim foram elaborados gráficos que procuram representar a distribuição das disciplinas dentro do curso, sejam elas obrigatórias ou optativas. Para a elaboração dos gráficos optamos, para o primeiro, referente ao rol de disciplinas obrigatórias (Gráfico 01), dividi-lo em conteúdos pedagógicos específicos para a docência, conteúdos específicos para a Geografia, estágios supervisionados, TCC e optativas. Já o segundo gráfico (Gráfico 02), complementa o primeiro ao subdividir as disciplinas optativas em conteúdos pedagógicos específicos para docência e conteúdos específicos para a Geografia.

Gráfico 1: Disciplinas obrigatórias do curso de Geografia Licenciatura da FAED - UDESC

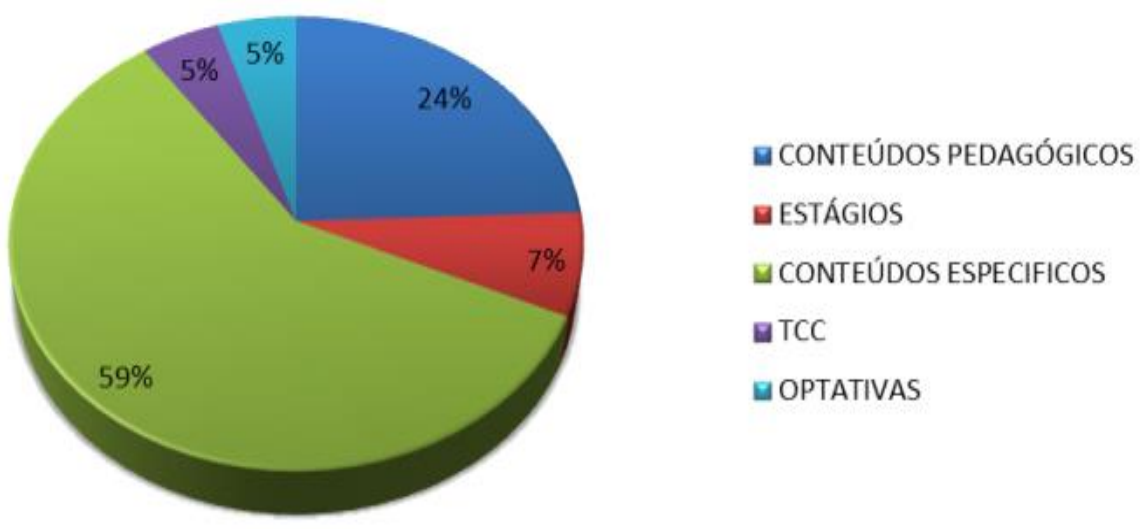

Fonte: Elaborado pelas autoras, 2019. 
Gráfico 1: Disciplinas optativas do curso de Geografia Licenciatura da FAED - UDESC

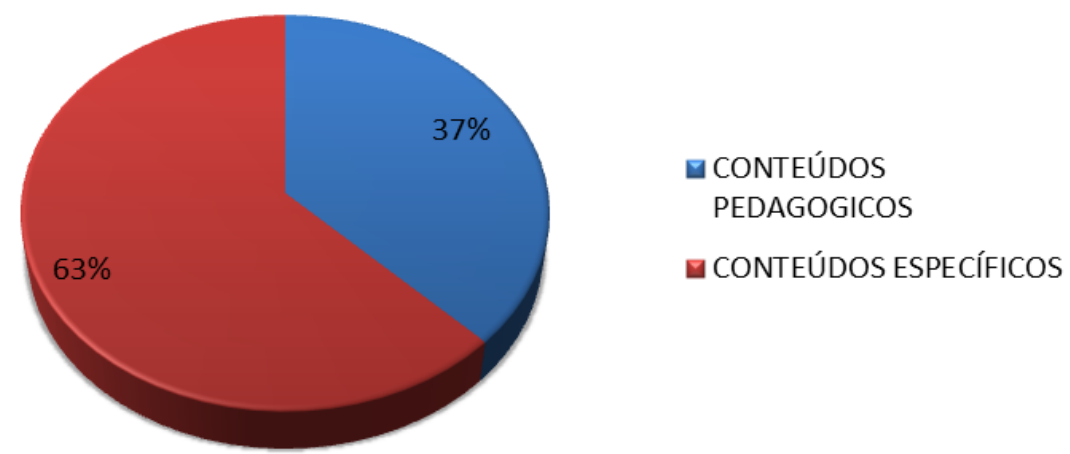

Fonte: Elaborado pelas autoras, 2019.

O PPC (2013) apresenta esta matriz curricular e suas disciplinas segmentadas também por áreas de conhecimento, nas quais os conteúdos são fracionados nos conhecimentos que abordam Geografia Física, Cartografia, Educação, Geografia Humana e Ensino de Geografia. Portanto, vê-se a proposta do atual desenho curricular de articular a teoria e prática perante a formação de professores/as e de sua identidade profissional, visto que Callai (2006) enfatiza, em "A articulação teoria-prática na formação do/a professor/a de Geografia”, a importância da articulação teoria-prática na formação docente do professor de geografia. Buscando compreender qual o papel deste profissional na sociedade atual e qual a realidade e as dificuldades que determinam o cotidiano das escolas no mundo atual. Entender as transformações que têm ocorrido no mundo, alterações nas dimensões de tempo e espaço, avanço da tecnologia e a estrutura das novas relações entre as pessoas são desafios a enfrentar. Este panorama requer que o professor de geografia "além de situar-se no mundo reconhecendo a sua identidade e pertencimento, compreenda os fenômenos que estão acontecendo e as formas como eles se concretizam nos espaços" (p. 144).

Dessa forma a construção da identidade profissional docente, além de percorrer dentro e fora do âmbito universitário e escolar, pode ser constituída através da ementa das disciplinas destinadas aos conteúdos pedagógicos voltados para a docência. Por isso nesta pesquisa optamos também por explanar e analisar as ementas das disciplinas obrigatórias direcionadas as áreas de conhecimento da Educação e do Ensino de Geografia, como: Educação Inclusiva, Organização e Gestão da Educação, Educação Ambiental, Práticas Curriculares em Geografia I, II e III, Didática Geral, Metodologia do Ensino em Geografia, Educação das Relações Étnico-raciais, Libras e Estágio Curricular Supervisionado em Geografia I, II e III. Além das disciplinas pedagógicas que compõe o rol de 
optativas, como: Educação de Jovens e Adultos, Psicologia da Educação, Educação e Sociedade, Filosofia da Educação, Mídias e Educação e Profissão docente. Com a intenção de manter uma organização metodológica de minha pesquisa realizo a análise das ementas de cada disciplina por sua respectiva fase/semestre de atuação.

São grandes os desafios entre a formação acadêmica e a atuação do/a professor/a no cotidiano da sala de aula. Existe uma complexidade de elementos que se articulam e que contribuem para o desenvolvimento da prática pedagógica. A trajetória da formação envolve a constituição da identidade profissional do/a professor/a, e precisa estar pautada numa abordagem que privilegie o mesmo como sujeito do processo de ensino, que construa sua prática num contínuo processo de reflexão sobre a atividade de ensinar com condições de enfrentar diferentes situações no seu cotidiano de trabalho. Uma formação que promova a autonomia profissional para que o/a professor/a seja capaz de produzir conhecimentos e articular teoria e prática.

Para além dos currículos, quando tratamos de formação docente, vale destacar, no âmbito acadêmico, a tríade: pesquisa, ensino e extensão. A formação do/a professor/a deve estar articulada com questões que atravessem o currículo do curso, expandindo o núcleo de seu trabalho profissional e considerando que a identidade docente é construída sob a influência de diversos itinerários. Entende-se que "não se pode desprezar o fato de que a identidade também se constitui a partir das representações que um grupo ou sociedade possui em torno da mesma" (COSTA E SILVA, 2011, p. 7850). Representações estas, dentro da universidade, que se constituem através de projetos de ensino, pesquisa e extensão, que são vivenciados nos diferentes espaços e laboratórios que os/as estudantes têm a oportunidade de experimentar ao longo da formação inicial.

Os desenhos curriculares do curso de Geografia Licenciatura, por meio de suas disciplinas ofertadas e suas atividades complementares, segundo o PPC (2013) procura desenvolver essa prática docente articulando as matérias entre si, propondo assim que a formação proporcione aos professores/as condições para que estes compreendam o contexto social no qual ocorre o processo de ensino/aprendizagem, onde há uma infinidade de interesses e valores que perpassam a educação do nosso país.

É preciso assegurar que a formação de professores possibilite ao profissional docente saber lidar com o processo formativo dos alunos em suas várias dimensões, além da cognitiva, englobando a dimensão afetiva, da educação dos sentidos, da estética, da ética e dos valores emocionais. (LEITE, 2006, p. 69). 
Esse processo formativo se inicia, primeiramente por meio dos desenhos curriculares propostos pelo curso de formação docente, visto que "o currículo é uma questão de saber, identidade e poder" (COSTA E SILVA, 2011, p. 7849) além de dispor desse caráter de papel formativo. Este de constrói a partir do indivíduo como sujeito, visando à prática de identidades que são partilhadas por estes sujeitos fundamentadas em cenários particulares que podem compreender sentimentos, atitudes e até expectativas perante o processo formativo profissional identitário do/a professor/a de Geografia (COSTA E SILVA, 2011).

\section{CONSIDERAÇÕES FINAIS}

Ao refletirmos acerca do objeto de estudo da ciência geográfica, que se constitui como o espaço geográfico, percebe-se que ao atuarmos como futuros/as professores/as de maneira fragmentada e individualizada dificulta a construção de conhecimentos que contribuem, para além da constituição da visão de mundo proposta pela ciência, assim como coadjuvam no processo formativo da identidade profissional docente, considerando que o trabalho e a identidade docente não têm como serem praticados de uma forma fragmentada ou também isolada, visto que faz parte de um coletivo heterogêneo que necessita ser destacado através das suas especificidades (OLIVEIRA, 2016).

Dessa forma, esta pesquisa problematiza os desenhos curriculares, do curso de Geografia Licenciatura, e como podem contribuir para a formação da identidade docente dos futuros professores e professoras no curso, tendo como objetivo primordial compreender de que maneira a organização do PPC e o desenho curricular, implantado em 2014, do curso de Geografia Licenciatura contribui para a formação da identidade docente. Ao analisarmos a potência dos desenhos curriculares na constituição da identidade profissional docente do/a estudante de Geografia, compreende-se a importância da constituição do Projeto Pedagógico do Curso, visto que o mesmo engloba a formação inicial dos licenciados para além do currículo.

São nas disciplinas pedagógicas que os/as licenciados/das tem o contato com os conteúdos e referenciais teóricos ligados as questões voltadas para o exercício da docência e a realidade da escola. Acredita-se que estas disciplinas contribuem para que os/as estudantes possam consolidar os primeiros passos para constituição da identidade profissional docente uma vez que se deparam com questões voltadas para as fronteiras do conhecimento ligado a formação inicial e continuada de professores/as, a realidade da Educação Básica e a compreensão do processo de ensino e 
aprendizagem das crianças e adolescentes. Estas disciplinas têm um papel fundamental na articulação da teoria e prática possibilitando a compreensão entre a geografia acadêmica e a geografia escolar, além da relação entre a universidade e a escola básica, propondo assim uma consolidação na formação inicial de professores e professores que atuarão na Educação Básica.

A presente pesquisa contribuiu para compreensão de que os desenhos curriculares e os atravessamentos do percurso de formação são fundamentais na constituição da identidade profissional docente do/a estudante de Geografia, e o Projeto Pedagógico do Curso tem um papel crucial na constituição do itinerário formativo dos/das licenciados/as, que vai para além do currículo. A constituição da identidade docente no percurso da formação inicial de professores/as é um processo fundamental para a constituição do sentido de pertencimento a uma categoria profissional dos professores/as e contribui principalmente no que diz respeito ao comprometimento com a profissão e ao projeto de educação no qual o/a professor/a se propõe a atuar ao adentrar um curso de licenciatura e enfim atuar na Educação Básica.

Esta pesquisa não busca e tampouco se atenta em conceber uma verdade absoluta acerca dos desenhos curriculares ou sobre a formação docente nos cursos de Geografia Licenciatura da FAED UDESC, uma vez que não se tem o propósito de idealizar uma utopia em relação à construção e elaboração da estrutura curricular ou do PPC. Acreditamos que a realidade da educação em nosso país, requer a organização de cursos de formação inicial de professores/as que assegurem uma formação sólida capaz de dar conta da construção da identidade profissional docente para a atuação dos/das licenciados/as enquanto professores/as que irão atuar nas escolas da Educação Básica.

\section{REFERÊNCIAS}

BRASIL. Constituição da República Federativa do Brasil. Brasília, DF, 1988. Disponível em: http://www.planalto.gov.br/ccivil_03/Leis/L9394.htm. Acesso em: 01 nov. 2017.

BRASIL. Lei de Diretrizes e Bases da Educação Nacional: LDB n 9.394. Brasília, DF: 1996. Disponível em: <http://portal.mec.gov.br/component/content/articleid:legislacoes>.Acesso em: 23 abr. 2017.

CAMPOS, Margarida de Cássia. A formação do professor de geografia: a difícil construção do saber/fazer docente. Geosaberes, Fortaleza, v.3, n.6, p. 3-15, jul./dez. 2012.

COSTA E SILVA, Géssica Peniche. Identidade profissional docente face às políticas e reformas curriculares para a formação de professores. EDUCERE , PUCPR, Curitiba, 2011. 
DOURADO, Luiz Fernando. Diretrizes curriculares nacionais para a formação inicial e continuada dos profissionais do magistério da educação básica: concepções e desafios. Edu. Soc., Campinas, v.36, nº. 131, p. 299-324, abr.-jun., 2002.

IMBERNÓN, Francisco. Formação Docente e Profissional: formar-se para a mudança e a incerteza. 9. ed. São Paulo: Cortez, 2011.

LEITE, Yoshie Ussami Ferrari. O lugar das práticas pedagógicas na formação dos professores. In: SILVA, Aida Maria, et al. (Orgs). Políticas educacionais, tecnologias e formação do educador: repercussões sobre a didática e as práticas de ensino. Recife, ENDIPE, 2006, p. 65-81.

$\begin{array}{lcccc}\text { MASSON, Gisele. Políticas De Formação De Professores: As Influências Do Neopragmatismo } \\ \text { Da } & \text { Agenda } & \text { Pósmoderna. } & 2009 . & \text { Disponível }\end{array}$ <https://repositorio.ufsc.br/xmlui/bitstream/handle/123456789/93077/274623.pdf?sequence=1\&isA llowed=y $>$. Acesso em: 21 ago. 2019.

OLIVEIRA, Suzana Ribeiro Lima. Formadores de profissionais em geografia e identidade(s) docente(s). Goiânia, GO, Universidade Federal de Goiás. 2016.

PIMENTA, Selma Garrido. Formação de professores: identidade e saberes da docência. In: PIMENTA, Selma Garrido. (Org). Saberes Pedagógicos e atividade docente. São Paulo: Cortez Editora, 1999. (p. 15-34).

ROCHA, Cléa Cardoso da. BRAGA, Maria Cleonice Barbosa. SANTOS, Francisco de Assis. Trajetórias de formação docente na licenciatura em geografia: da instrumentalização técnica ao intelectual crítico. Geosaberes, Fortaleza, v.5, n.10, p. 76-86, jul./dez. 2014.

SILVA, Daiana Bastos da. O plano de viver sem limite como estratégia da governabilidade democrática: a constituição do sujeito com deficiência como cidadão. Osório, 2016.

SILVA, Eliane Paganini da. MANO, Amanda de Mattos Pereira. Identidade profissional docente: concepções de futuros professores. Ensino Em Re-Vista. Uberlândia, MG. V.25, n.1, p. 184-208, jan./abr. 2018.

SCHEIBE, Leda; BAZZO, Vera Lúcia. Diretrizes curriculares nacionais para os cursos de licenciatura no brasil: da regulamentação aos projetos institucionais. Educação em perspectiva. Viçosa, v.4, n.1, p. 15-36, jan/jun. 2013.

UDESC/FAED, Universidade do Estado de Santa Catarina/Centro de Ciências Humanas e da Educação. Departamento de Geografia. Projeto Pedagógico do Curso de Graduação em Geografia - Licenciatura. Florianópolis, 2013.

VEIGA, Ilma Passos Alencastro. Docência: Formação, Identidade Profissional e Inovações Didáticas. In: SILVA, Aida Maria Monteiro [et al.]. (Orgs). Educação Formal e Não Formal, processos formativos e saberes pedagógicos: desafios para a inclusão social. Encontro Nacional de Didática e Práticas de Ensino, ENDIPE, Recife - PE, 2006. (p. 467-484). 
VEIGA, Ilma Passos Alencastro. Educação básica e educação superior: Projeto Político Pedagógico. Campinas, SP: Papirus, 2004.

VOLSI, Maria Eunice França. Políticas para a formação de professores da educação básica em nível superior: em discussão as novas diretrizes nacionais para a formação dos profissionais do magistério. XXIV Seminário Nacional UNIVERSITAS/BR. UEM. Maringá, 2016. 